\title{
Urine Chlorin of Infants Nursed with Human Milk of Different Arakawa's Reaction.*
}

\author{
98th Report of the Peroxidase Reaction.
}

By

\author{
Misao Ishii. \\ (石井 節) \\ (From the Department of Pediatrics, Faculty of Medicine, \\ Töhoku Imperial University, Sendai. \\ Director: Prof. A. Sato.)
}

The chlorin intaken is, as A mbergi) or Rietschel ${ }^{2)}$ or Noeggerath-Eckstein ${ }^{3}$ writes from a survey of literature, in a normal metabolism of infants, chiefly excreted in the urine, and its quantity in the urine will depend usually upon its amount in the food. And the chlorin is poor in the urine of infants, for human milk is chlorinpoor and the artificially fed infant excretes, due to a larger amount of chlorin in the food, a larger quantity of chlorin in the urine than the breast-fed infant. Walther Freund $d^{4}$ introduced in his exhaustive treatise the results of different authors concerning the urine chlorin in breast-fed infants, besides interesting experiments performed by Michel (Cf. Table 1). Michel estimated, he cites, chlorine intake of

* Arakawa-positive may be used in two different senses. One of these is: Arakawa-positive in a biochemical sense. A sample of human milk is said to have become. Arakawa-positive, when it becomes blue on the addition of A ra ka w a's reagent. There it means that the sample is not negative to Arakawa's reaction. Arakawa-positive in a clinical sense: A sample of human milk is clinically Arakawa-positive only when it shows such a reaction as $\#$ or $\#$ in one minute of the addition of $A r a k$ a wa's reagent. Another sample of human milk may be Arakawa-positive in the first described sense, but yet clinically negative.

1) S. A m berg, A bt's Pediatries, 1923 Phil. \& Lond., 4, 1111.

2) H. Rietschel, Handbuch der Kinderheilkunde, compiled by $\mathrm{P} f$ a und ler and Schlos smann, 1923 Lpg., Vol. 1, 340.

3) C. Noeggerath and A. Eekstein, Handbuch der Kinderheilkunde, compiled by Pfaunder and Schlossmann, 1923 Lpg., Vol. 4, 30.

4) W. Freund, Jahrb. f. Kinderh., 1898, 48, 137. 
infants and determined chlorin in their urine and stools and saw a retention of the salt in the infantile organism. Freund himself experimented on it and asserted Michel's conclusion. Schiff saw, Fre und cites, a considerable increase of chlorine content of urine in an infant nursed by a feverish mother and attributed the cause to an increase of chlorine content in the mother's milk due to chlorine retention caused by fever in the maternal body.

Table 1.

Chlorine data of different authors eited in the paper of W. Fre und.

\begin{tabular}{l|ll}
\hline \multicolumn{1}{c|}{ Authors } & \multicolumn{1}{|c}{ NaCl content in urine of infants } \\
\hline Dorn & $0.033-0.497 \%$ (immediately after the delivery) \\
\hline Martin and Ruge & $0.107 \%$ & $(0-10$ days) \\
\hline Hecker and Vogel & $0.089-0.150 \%$ & (3-17 days) \\
\hline Parrot and Robin & $0.069 \%$ & (0-8 days) \\
Ultzmann and Pollack & $0.090 \%$ & (9-30 days) \\
\hline
\end{tabular}

Now I have investigated in this paper the relation between Ara$\mathrm{k}$ a w a's reaction and the chlorine content of the urine of breast-fed infants.

\section{Materials and Method of Investigation.}

Materials were chiefly collected in the morning (9-12 A. M.) from the infantile out-patients of our Department. Only 22 out of all my 110 samples were obtained from healthy male infants at a baby show held in this city on May 5th. last year.

The chlorine method used for this purpose is that of St. Rusznyak. ${ }^{5)}$

\section{Result of Experiment.}

All the cases examined are given in Table 2.

As is shown in Table 3, the chlorine content in the urine of breastfed infants is in Arakawa-positive cases $38.0 \mathrm{mgrms} . \%$, and in negative cases $41.1 \mathrm{mgrms} . \%$. If, however, negative cases are grouped into cases with intermediate reaction and cases with completely or al-

5) St. Ruszny a k, Biochem. Z., 1921, 114, 23. 


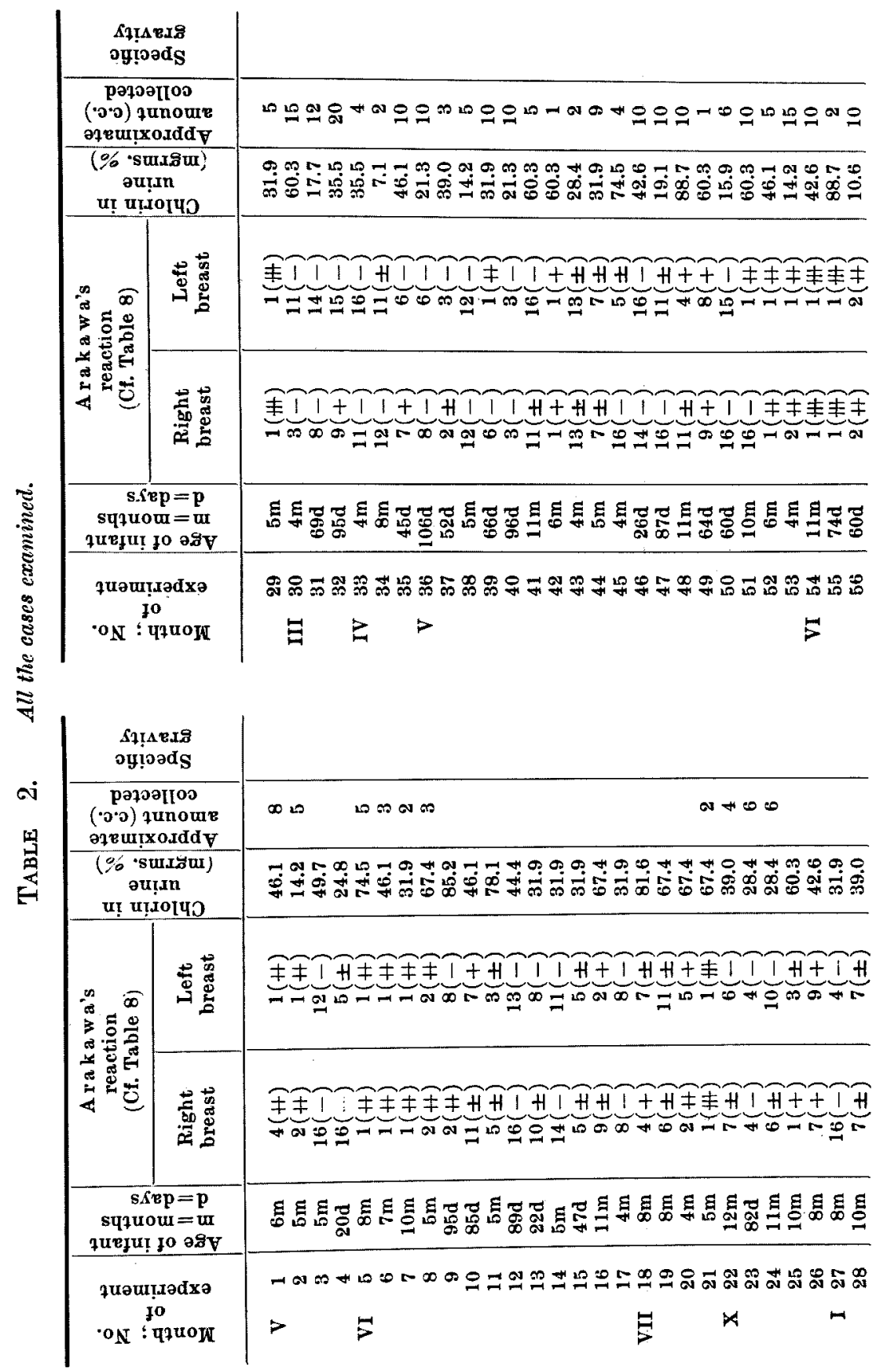




\begin{tabular}{|c|c|c|}
\hline \multicolumn{2}{|c|}{ 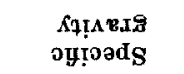 } & 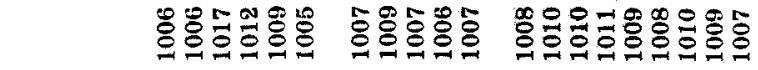 \\
\hline \multicolumn{2}{|c|}{ 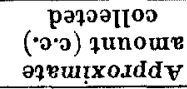 } & 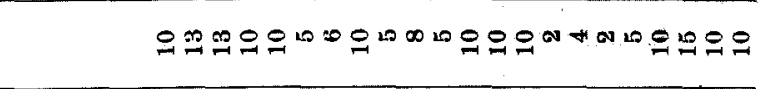 \\
\hline \multicolumn{2}{|c|}{ 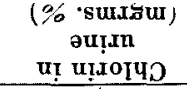 } & 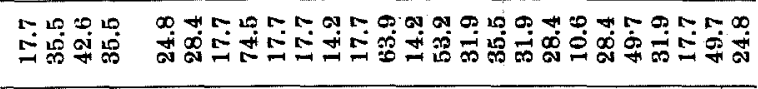 \\
\hline \multirow{2}{*}{ 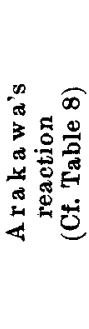 } & 壱 & 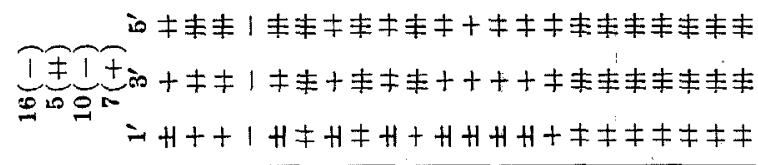 \\
\hline & 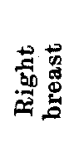 & 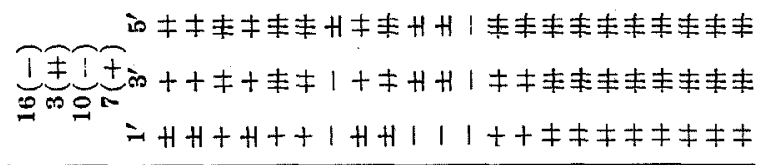 \\
\hline \multicolumn{2}{|c|}{ 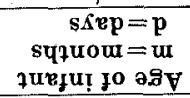 } & 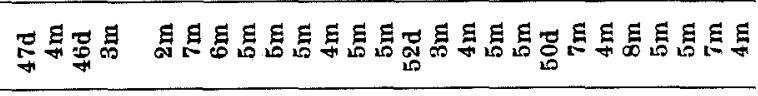 \\
\hline \multicolumn{2}{|c|}{ 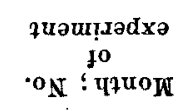 } & 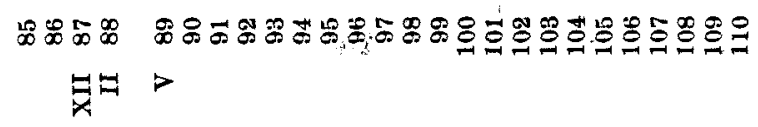 \\
\hline
\end{tabular}

\begin{tabular}{|c|c|c|}
\hline \multicolumn{2}{|c|}{ 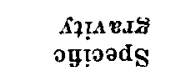 } & 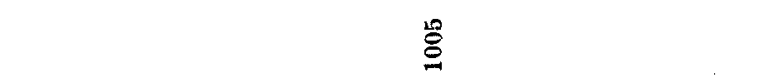 \\
\hline \multicolumn{2}{|c|}{ 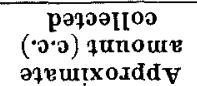 } & 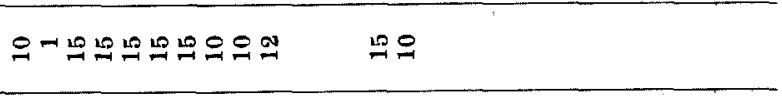 \\
\hline \multicolumn{2}{|c|}{ 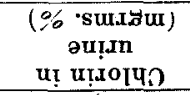 } & 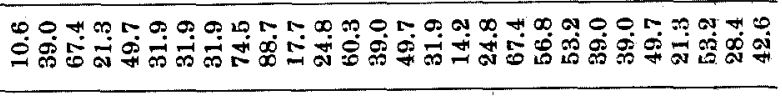 \\
\hline \multirow{2}{*}{ 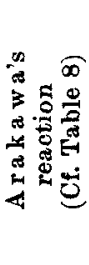 } & 离 & 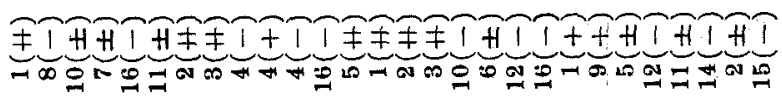 \\
\hline & 䓛若 & 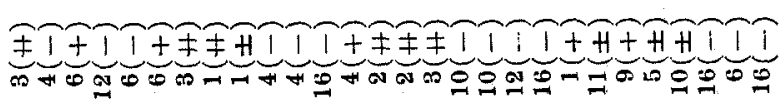 \\
\hline \multicolumn{2}{|c|}{ 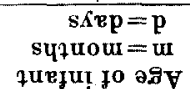 } & 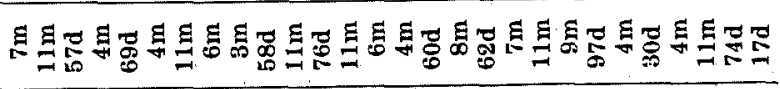 \\
\hline \multirow{2}{*}{\multicolumn{2}{|c|}{ 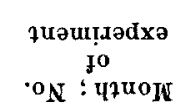 }} & 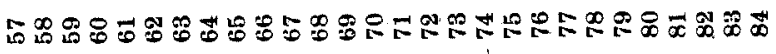 \\
\hline & & 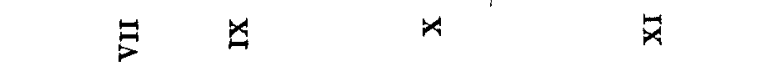 \\
\hline
\end{tabular}


TABLE 3.

A rakawa's reaction and chlorine content in urine of breast-fed infants.

\begin{tabular}{c|c|c|c|c|c|}
\hline & $\begin{array}{c}\text { Arakawa- } \\
\text { positive cases }\end{array}$ & Arakawa-negative cases & $\begin{array}{c}\text { Average } \\
\text { of all } \\
\text { the cases }\end{array}$ \\
\hline $\begin{array}{c}\text { Chlorine } \\
\text { content } \\
\text { in urine } \\
(\text { mgrms. \%) }\end{array}$ & 38.0 & 41.1 & $\begin{array}{c}\text { Intermediate } \\
\text { reaction }\end{array}$ & $\begin{array}{c}41.5 \\
\left(\begin{array}{c}75 \text { cases in } \\
\text { numb er }\end{array}\right)\end{array}$ & 40.4 \\
\cline { 3 - 5 }$\left(\begin{array}{c}27 \text { cases in } \\
\text { number }\end{array}\right)$ & $\left(\begin{array}{c}83 \text { cases in } \\
\text { number }\end{array}\right)$ & $\begin{array}{c}\text { Completely or } \\
\text { almost com- } \\
\text { pletely nega- } \\
\text { tive reaction }\end{array}$ & $\begin{array}{c}37.3 \\
\left(\begin{array}{c}8 \text { cases in } \\
\text { number }\end{array}\right)\end{array}$ &
\end{tabular}

most completely negative reaction, it is $41.5 \mathrm{mgrms} . \%$ in the former, while it is 37.3 mgrms. $\%$ in the latter.

TABLE 4.

Human milk chlorin according to the intensity of A rakawa's reaction.

\begin{tabular}{|c|c|c|c|}
\hline & $\begin{array}{l}\text { Arakawa- } \\
\text { positive milks }\end{array}$ & $\begin{array}{c}\text { Arakawa- } \\
\text { negative milks }\end{array}$ & $\begin{array}{c}\text { Completely or almost } \\
\text { completely negative } \\
\text { milks }\end{array}$ \\
\hline $\begin{array}{c}\text { Chlorine } \\
\text { content in } \\
\text { human milk } \\
\text { (mgrms. } 96 \text { ) }\end{array}$ & $\begin{array}{c}34.5 \\
(34.9)^{*} \\
266(276)^{*} \text { cases } \\
\text { in number }\end{array}$ & $\begin{array}{c}48.2 \\
(50.7)^{*} \\
532(624)^{*} \text { cases } \\
\text { in number }\end{array}$ & $\begin{array}{l}61.3 \\
(63.6)^{*}\end{array}$ \\
\hline
\end{tabular}

* The data and the number of all the cases including samples within one month after the delivery.

Now, the chlorin intaken by those infants will be examined (Cf. Table 4). The chlorine content of mother's milk is in Arakawa-positive cases 34.5 mgrms. $\%$ (or 34.9 mgrms. $\%$, if the cases within one month of the delivery are included among them), in Arakawa-negative cases 48.2 mgrms. \% (or 50.7 mgrms. \%, if the cases within one month of the delivery are included among them), and in completely or almost completely negative cases 61.3 mgrms. $\%$ (or 63.6 mgrms. \%, if the cases within one month of the delivery are included among them). Though one whole day's amount cannot be cited here, yet we can obtain an idea of the chlorine metabolism in those breast-fed infants, if the chlorine content in mother's milk and that in infant's urine are compared with each other. Infants of Arakawa-positive mothers with 34.5 or 34.9 mgrms. \% of chlorin in their milk excrete the urine with 38.0 
mgrms. $\%$ of the salt, and those with Arakawa-negative mothers with 48.2 or 50.7 mgrms. \% of chlorin in their milk excrete the wine with 41.1 mgrms. $\%$, while those with completely or almost completely Arakawa-negative mothers with 61.3 or $63.6 \mathrm{mgrms}$. \% of chlorin in their milk excrete the urine with $37.3 \mathrm{mgrms}$. \%.

If I make bold to make the following substractions*:

a. $34.5-38.0=-3.5 ; \quad$ b. $48.2-41.5=+6.7 ; \quad$ c. $61.3-37.3=+24.0$, then I know only too well that these figures obtained do not show anything concrete. Yet the difference among these three figures: $-3.5,+6.7$ and +24.0 is, I believe, of important significance. The figure in Arakawa-positive and -negative cases are of the same order (3.5 resp. 6.7), but the sense is entirely different $(-3.5$ resp. +6.7 ). As to the completely negative cases; the order of the figures is different (24.0 in contrast to 3.5 or 6.7). The relation among these figures has led me to draw such diagrams as are shown below (Cf. Figure).

Figure. Schematic presentation of chlorine intake and excretion in infants fed on Arakawa-positive and-negative human milk.

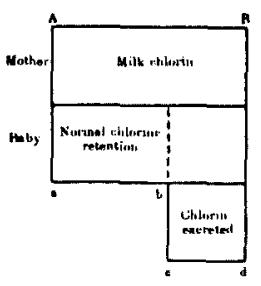

Arakawa-positive cases

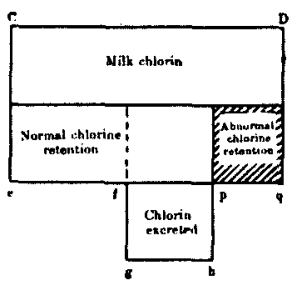

Intermediate cases

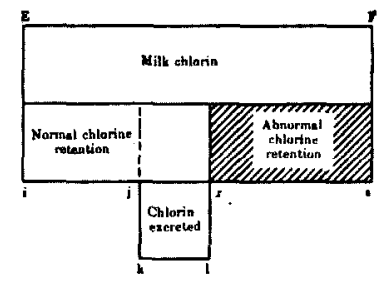

Completely or almost completely negative cases

$$
\mathrm{AB}<\mathrm{CD}<\mathrm{EF} \quad \mathrm{ab}=\mathrm{ef}=\text { if } \quad \mathrm{gh}>\mathrm{cd}>\mathrm{kl} \quad \mathrm{rs}>\mathrm{pq}
$$

In drawing these diagrams, I have taken also Ume $\mathrm{m}$ u ra's opinion into consideration.

Ume $\mathrm{mura}^{6}$ ) who has been investigating in this Laboratory the relation between A rakawa's reaction and mother's chlorine content in urine, is of the opinion that an abnormal chlorine retention will occur in Arakawa-negative mothers.

6) H. Umemura, to be published in this Journal. His opinion is based on his own result of the investigation of urine chlorin.

His result is :-

About 0.9 grms. $\%$ in the case of Arakawa-positive mothers,

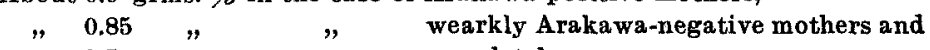

" 0.7 " completely " " "

* These figures are not to be added or substracted of course, but the results will be convenient to give a rough idea of the state to be described here. 
If the abnormal large chlorine figure of Arakawa-negative mothers is the result of such a retention, and if $I$ can assume again an abnormal chlorine retention in the body of babies fed with Arakawa-negative milk, then the relation shown in the accompanying figure (Cf. Figure) will not be altogether unnatural.

The Figure (Cf. Figure) shown above is of course not based on the quantitative estimation of one whole day's amount of milk chlorin or urine chlorin, yet, if milk secretion or better milk intake and urine excretion are assumed to be of an equal amount in infants of Arakawa-positive, Arakawa-negative mothers and those with intermediate reactions, then the figure will show a rough idea of chlorine metabolism of those infants.

Remarks.

1. By way of appendix, monthly variation of chlorine content in the urine of breastfed infants and the relation between the period of lactation and chlorine content of their urine are shown in Tables 5 and 6 (Cf. Tables 5 and 6 ).

Table 6.

Periods of lactation and chlorin in urine of infants according to A rakawa's reaction.

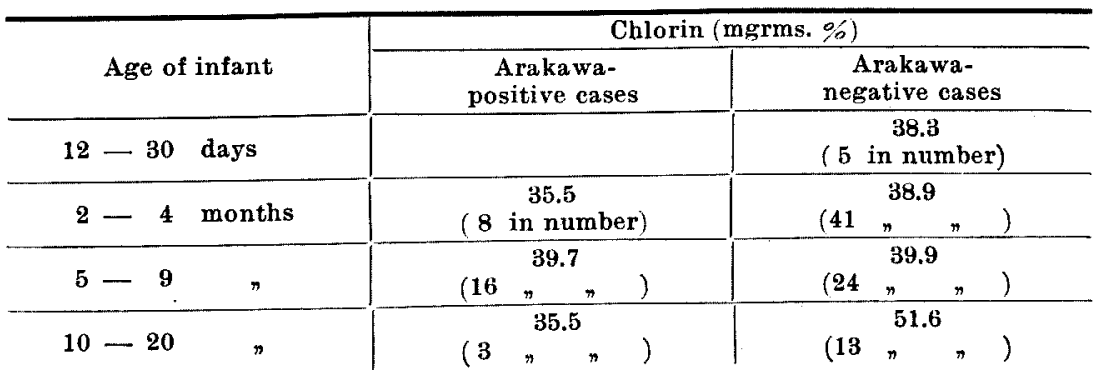

TABle 5.

Monthly variation of chlorine content in urine of infants according to Arakawa's reaction.

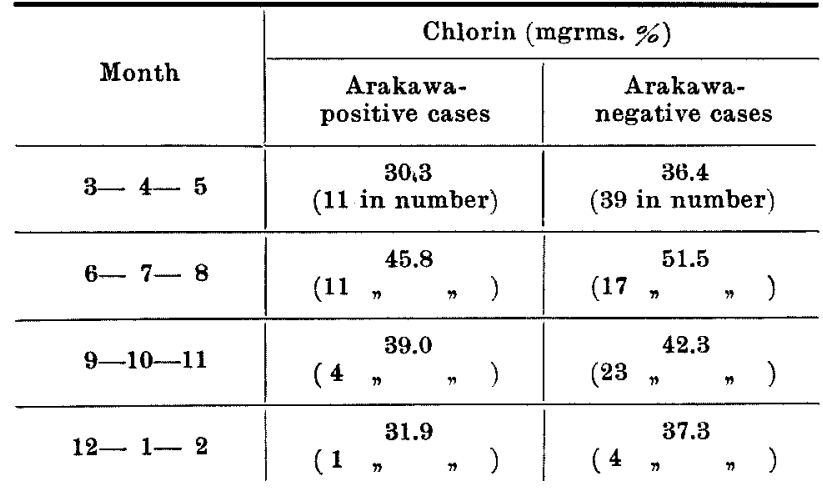


2. Chlorine content in the urine of 6 infants fed with allaitement mixte (mother's milk and cow's milk) is, as is shown in Table 7, remarkably higher than that of breast-fed infants (Cf. Table 7).

TABLE 7.

Chlorin in urine of the cases with allaitement mixte.

\begin{tabular}{c|c|c|c}
\hline No. of exp. & $\begin{array}{c}\text { Age of infant } \\
\text { m=months }\end{array}$ & $\begin{array}{c}\text { Chlorin in urine } \\
\text { (mgrms. \%) }\end{array}$ & Specific gravity \\
\hline 1 & $11 \mathrm{~m}$ & 149.1 & 1012 \\
2 & $7 \mathrm{~m}$ & 334.0 & 1013 \\
3 & $12 \mathrm{~m}$ & 134.9 & 1005 \\
4 & $10 \mathrm{~m}$ & 170.4 & 1014 \\
5 & $8 \mathrm{~m}$ & 113.6 & 1013 \\
6 & $4 \mathrm{~m}$ & 156.2 & 1010
\end{tabular}

Table 8.

Table of signs for showing different A ralk aw a's reaction.

$\begin{array}{lllll}1^{\prime} & 2^{\prime} & 3^{\prime} & 4^{\prime} & 5^{\prime}\end{array}$

1. $1($ m) stands for $\#$ \# $\#$ H

2. $1(H), H$ H H H H

3. $2(H) \geqslant H+H$ H $H$

4. $3(+t) 》 H+H$ H H

5. 4(H) $\#+H+H+H$

6. $5(H)$ stands for $H+H+H$

7. $1(+)$, + H H H H

8. $2(+),+H+H$

9. $3(+) "++4+H$

10. $4(+) \Rightarrow+H+H+H$

11. $5(+) "+++4$ H

12. $6(+),++4$ +

13. $7(+),++H+H$

14. $8(+) \Rightarrow+++H+H$

15. $9(+),+++H+H$

16. $10(+),+++++$

17. $11(+) "+++++$

18. $1( \pm), \pm+H+4$

19. $2( \pm) \quad$ $\pm+H+H$

20. $3( \pm)$ $\pm+H+H$

21. $4( \pm) \rightarrow \pm++H$

22. 5(士) $" \pm++H+H$

23. $6( \pm), \pm+++H$

24. $7( \pm), \pm++++$

\begin{tabular}{|c|c|c|c|c|c|c|c|}
\hline 25. & $8( \pm)$ & $n$ & $\begin{array}{l}\mathbf{1}^{\prime} \\
\pm\end{array}$ & $\begin{array}{l}2^{\prime} \\
\pm\end{array}$ & $\begin{array}{l}3^{\prime} \\
+\end{array}$ & $\begin{array}{r}4^{\prime} \\
H\end{array}$ & \# \\
\hline 6. & $9( \pm)$ & $\pi$ & \pm & \pm & + & $H$ & $H$ \\
\hline 27. & $10( \pm)$ & $\pi$ & \pm & \pm & + & + & $H$ \\
\hline 28. & $11( \pm)$ & $n$ & \pm & \pm & + & + & + \\
\hline 29. & $12( \pm)$ & $n$ & \pm & \pm & \pm & + & $H$ \\
\hline 30. & $13( \pm)$ & $"$ & \pm & \pm & \pm & + & + \\
\hline 31. & $14( \pm)$ & $n$ & \pm & \pm & \pm & \pm & + \\
\hline 32. & $15( \pm)$ & $n$ & \pm & \pm & \pm & \pm & \pm \\
\hline 33. & $1(-)$ & \# & - & \pm & + & $H$ & $H$ \\
\hline 34. & $2(-)$ & $n$ & - & \pm & + & $H$ & H \\
\hline 35. & $3(-)$ & $n$ & - & \pm & + & + & $H$ \\
\hline 36. & $4(-)$ & $\pi$ & - & \pm & + & + & + \\
\hline 37. & $5(-)$ & $n$ & - & \pm & \pm & + & $H$ \\
\hline 38. & $6(--)$ & $n$ & - & \pm & \pm & + & + \\
\hline 39. & $7(-)$ & $\#$ & - & \pm & \pm & \pm & + \\
\hline 40. & $8(-)$ & $n$ & - & \pm & \pm & \pm & \pm \\
\hline 41. & $9(-)$ & $n$ & - . & - & \pm & + & $H$ \\
\hline 42. & $10(-)$ & » & - & - & \pm & + & + \\
\hline 43. & $11(-)$ & $\pi$ & - & - & \pm & \pm & + \\
\hline 44. & $12(-)$ & $\Rightarrow$ & - & - & \pm & \pm & \pm \\
\hline 45. & $13(-)$ & $n$ & - & - & - & \pm & + \\
\hline 46. & $14(-)$ & $n$ & - & - & - & \pm & \pm \\
\hline 47. & $15(-)$ & n & - & - & - & - & \pm \\
\hline 48. & $16(-)$ & \# & - & - & - & - & - \\
\hline
\end{tabular}

Explanation to the Table:-

Take, for instance, the sign: 2(H). This stands for Arakawa's reaction with the course $(H) 1^{\prime}(H) 2^{\prime}(H) 3^{\prime}(H) 4^{\prime}(H) 5^{\prime}$. The sign does not express any prompt result of the reaction, so the prompt reaction of the sign : $2(+H)$ may be $(-) 0^{\prime},( \pm) 0^{\prime},(+) 0^{\prime}$, or even $(H) 0^{\prime}$, but this will not matter much, as the result of the reaction in one minute is the most important. 


\section{Summary.}

In this paper the relation between Arakawa's reaction and the chlorine content of the urine of breast-fed infants is investigated. The chlorine content in the urine of breast-fed infants is $38.0 \mathrm{mgms} . \%$ in Arakawa-positive cases and $41.5 \mathrm{mgrms} . \%$ or $37.3 \mathrm{mgrms} . \%$ in intermediate or completely or almost completely negative cases. And viewed from the chlorine figures of milk of mothers with different A rakawa's reaction and those in the urine of breast-fed infants nursed with milks of different Arakawa's reaction, it is probable that an abnormal chlorine retention occurs in the body of babies fed with Arakawa-negative milk; more so, if U me mu ra's opinion is taken into consideration.

\section{Conclusion.}

There is an abnormal chlorine retention in the body of babies fed with Arakawa-negative milk. 